\title{
Prevalence, organ distribution and antimicrobial susceptibility profile of Salmonella isolated from chickens purchased from markets in selected dis- tricts of West Shoa, Ethiopia
}

Edilu Jorga Sarba', Kebene Kudama ${ }^{2}$, Morka Dandecha ${ }^{3}$, Lencho Megersa ${ }^{3}$, Bizunesh Mideksa Borena ${ }^{1}$, Endrias Zewdu Gebremdhin ${ }^{1}$

${ }^{1}$ Ambo University, College of Agriculture and Veterinary Sciences, Department of Veterinary Science, P. O. Box 19, Ambo, Ethiopia

${ }^{2}$ Adaberga District Agriculture Office, Livestock and Fishery Agency, West Shewa Zone, Oromia region, Ethiopia

${ }^{3}$ Ambo University, College of Agriculture and Veterinary Sciences, Department of Veterinary

Laboratory Technology, P. O. Box 19, Ambo, Ethiopia

*Corresponding author, Email: jedilu8@gmail.com, Tel.: +251911957036

\begin{abstract}
Salmonella is one of the major causes of heavy losses in chicken and foodborne diseases worldwide. The current study was conducted from November 2015 to May 2016 to estimate the prevalence of Salmonella and determine the antimicrobial susceptibility of isolates in chickens. Chickens $(n=205)$ were purchased from local markets of five selected districts of West Shoa Zone, Central Ethiopia. Following clinical examination, chicken were euthanized and 2-3 ml of blood sample was collected immediately. Then after postmortem examination, samples were collected from the liver, kidney, ovary, and spleen. The slide agglutination test was used to assess the seroprevalence of Salmonella antibodies. Isolation of Salmonella was performed according to the ISO-6579 procedure. The isolates were subjected to antimicrobial susceptibility testing (using 13 antimicrobial drugs) following the Kirby-Bauer disc diffusion method. The seroprevalence of Salmonella antibodies was $63.5 \%$ (95\% CI: 55.9-70.5). The isolation rate of Salmonella was 19.0\% (95\% CI: 13.9-20.1) at the chicken level and $7.3 \%$ (95\% CI: 5.5-9.4) at the organ level. The detection rate was $11.2 \%, 7.0 \%, 6.1 \%$, and $4.4 \%$ for spleen, liver, ovary, and kidney, respectively. The majority of the Salmonella isolates were susceptible to norfloxacin (97.4\%) and chloramphenicol (92.3\%). All the 39 isolates were resistant to amoxicillin, tetracycline, and nitrofurantoin. Three multidrug resistance patterns to six antimicrobial classes were observed. Four isolates were resistant to five antimicrobial classes. Therefore, regular surveillance of Salmonella and its antimi-
\end{abstract}


crobial resistance is needed for a better understanding of the epidemiological dynamics. Awareness creation for chicken farmers about improving farming practices and the risks of antimicrobial resistance warrants special attention.

Keywords: Antimicrobial susceptibility; Chicken; Prevalence; Salmonella; Ethiopia

\section{Introduction}

Salmonellae are Gram-negative bacteria that are facultative intracellular human and animal pathogens and members of the family Enterobacteriaceae. Salmonella Gallinarum and S. Pullorum are the highly host-adapted serovars affecting birds.S. Enteritidis and S. Typhimurium are the common serotypes causing disease in humans and animals (Gal-Mor, 2019). Salmonellosis is an infection ranging from subclinical to acute fatal septicemia or chronic diarrhea and death (Quinn et al., 2011). In Ethiopia, salmonellosis is one of the important diseases of poultry reported from local and exotic chickens (Aragaw et al., 2010; Chaka et al., 2012; Kindu, and Addis, 2013). Fowl typhoid, which is caused by $S$. Gallinarum is a per-acute, acute, or chronic disease affecting mostly adult chickens, whereas pullorum disease, caused by $S$. Pullorum, affects young chickens of mostly 2-3 weeks of age (Parveen et al., 2007).

In Ethiopia, fowl typhoid and pullorum diseases are mentioned to cause heavy economic losses through mortality, morbidity, and reduced productivity (Chanie et al., 2009). Poultry salmonellosis has the ability of both vertical and horizontal transmission, which complicates the spread and control of the disease. As a result, layer chickens can become sub-clinically infected carriers and pass the infection to their embryo in the egg (Muktaruzzaman et al., 2010). Other Salmonella serovars such as S. Typhimurium might also colonize the gastrointestinal tract of adult poultry asymptomatically (Gal-Mor, 2019). There are several reports on the detection of non-typhoidal Salmonella serovars from chicken samples (Molla et al., 2003; Eguale, 2018), as poultry is the major source of foodborne salmonellosis for humans (Sanchez et al., 2002).

On the other hand, Salmonella species could acquire antimicrobial resistance (AMR). The resistant strains are non-treatable with currently available antimicrobials, thus are serious global public health concerns both in humans and food animals (Parveen et al., 2007). In Ethiopia, the veterinary drug regulation and guidelines are not well developed and there is no enforcing the standard to 
practice responsible and prudent use of antimicrobials. As a result, indiscriminate use of antimicrobials, the sale of counterfeit drugs, the involvement of untrained personnel, and illegal drug market are big challenges (DACA, 2009). Moreover, as the veterinary service is not well developed, chicken owners have a practice of treating sick chickens using antimicrobials either from veterinary or medical pharmacies (Sambo et al., 2015; Tufa et al., 2018).

Culture-based and serological studies detected Salmonella Gallinarum, S. Pullorum, and other serovars from chicken in Ethiopia previously (Aragaw et al., 2010; Berhe et al., 2012; Dagnew et al., 2020). There is also a report on the existence of multidrug-resistant Salmonella strains in chicken farms (Bekele and Ashenafi, 2010). However, there is little information about the prevalence and antimicrobial resistance of Salmonella species from chicken in Ethiopia (Molla et al., 2003, Eguale, 2018) and no data is available in the study area. Thus, for a better understanding of the situation, and to make an evidencebased decision, investigation in this aspect will have a significant contribution. Therefore, the objectives of the present study were to estimate the prevalence of Salmonella and to determine antimicrobial susceptibility of the isolates in selected districts of West Shoa, Central Ethiopia.

\section{Materials and methods}

\section{Description of the Study Area}

Chickens were purchased from local markets of Ambo, Holeta, Guder, Ijaji, and Dire Inchini districts of the West Shoa Zone, Oromia, Ethiopia. Ambo is an administrative center of the Ambo district and center of West Shoa Zone located $114 \mathrm{Km}$ West of Addis Ababa. It has a midland altitude. Holeta is located $40 \mathrm{Km}$ west of Addis Ababa and Dire Inchini is located $70 \mathrm{Km}$ southwest of Ambo, both are in highland altitude range. Guder and Ijaji are located $15 \mathrm{Km}$ and $80 \mathrm{Km}$ West of Ambo, respectively, and both are in the tropical climate. All the study districts experience a bimodal rainfall pattern. The chicken population of each district is approximately between 350, 000 to 500,000 (Etefa and Dibaba, 2011). 


\section{Study animals}

Chickens of both sexes and local and hybrid breeds managed under the backyard or small-scale management system were included. The chickens in this system, scavenge their feed with a limited supplement and often share the same house with humans or other livestock. Chickens were categorized as young ( $\leq 6$ months) and adult ( $>6$ months) based on their age (Calnek et al., 1991). Chickens with clinical signs of diseases such as decreased appetite, depression, weight loss, ruffled feathers, and watery to mucoid diarrhea, dehydration, and anemia were categorized as clinically sick and otherwise apparently healthy.

\section{Study design and sample size determination}

A cross-sectional study was conducted from November 2015 to May 2016. The sample size was determined using Thrusfield (2007) formula with an expected prevalence of 8\% (Aragaw et al., 2010) and with 0.05 precision. Accordingly, the calculated sample size was 113 chickens, but 205 chickens were considered for this study. Eighty-four clinically sick were purchased purposely and 121 apparently healthy chickens were randomly selected and purchased from local markets. Sick and healthy chickens were separately transported in a cage with adequate space and ventilation. Chickens were slaughtered immediately upon arrival, but whenever there is a delay they were kept for a maximum of one day in Ambo University in a room with adequate living space, ventilation, and feed and clean water in ad libitum.

\section{Postmortem examination}

Post mortem examination was performed according to procedures by Chauhan and Roy (2007). The cervical dislocation was used to euthanize chickens. Following slaughtering, the gross lesions on the visceral organs were recorded.

\section{Sample collection}

Approximately 2-3 $\mathrm{ml}$ of the blood sample was collected immediately following euthanasia from each chicken in a new plain vacutainer tube. The blood samples were kept in a slant position at room temperature overnight. After $24 \mathrm{hrs}$. of clotting, the sera were subjected to centrifugation at 1000 RPM for 10 minutes and sera were collected using sterile Pasteur pipettes in cryovial tubes, labeled and stored frozen at $-20^{\circ} \mathrm{C}$ until tested. A total of 741 samples comprising liver $(n=205)$, 
spleen $(n=205)$, kidney $(n=205)$ and ovaries $(n=131)$ was sampled. About $25 \mathrm{~g}$ of each organ was collected from the internal portion aseptically in a sterile polyethylene zipped plastic bag (Falconpack, UAE). The samples were kept at $+4^{\circ} \mathrm{C}$ for a maximum of $24 \mathrm{hrs}$ until culturing.

\section{Serological examination}

A serum slide agglutination test was performed following the test procedure described by OIE (2012). The sera and the reagent (crystal violet stained Salmonella Gallinarum antigens) were brought to room temperature $\left(22 \pm 5^{\circ} \mathrm{C}\right)$ before use. Thirty microliters of the reagent and equal volume of the serum were gently mixed on a sterile slide by rocking and rotating for about 2-3 minutes. Any degree of agglutination was taken as evidence of seropositivity. The serological test was performed at the National Veterinary Institute, Bishoftu, Ethiopia.

\section{Isolation and identification of Salmonella}

Isolation of Salmonella was performed as recommended by ISO 6579 (2002) Amendl: 2007. Tissue samples were crushed by gentle maceration in polyethylene zipper bag mixed with buffered peptone water (BPW) in a ratio of 1: 9 and is incubated at $37{ }^{\circ} \mathrm{C}$ for $24 \mathrm{hrs}$. Then, $0.1 \mathrm{ml}$ aliquots were inoculated into tubes containing $10 \mathrm{ml}$ Rappaport Vassiliadis (RV) broth (HiMedia, Pvt. Ltd., India) and are incubated for $24 \mathrm{hrs}$ at $42{ }^{\circ} \mathrm{C}$. Xylose Lysine Deoxycholate Agar (XLD) and Brilliant Green Agar (BGA) (HiMedia, Pvt. Ltd., India) plates were inoculated in parallel from the RV broths and incubated for $24-48 \mathrm{~h}$ at $37^{\circ} \mathrm{C}$. Up to five suspect colonies with typical Salmonella morphology on XLD (red colonies with/without black spots) and BGA (pink colonies) were streaked onto nutrient agar plates and incubated at $37{ }^{\circ} \mathrm{C}$ for $24-48 \mathrm{hrs}$. Finally, colonies from nutrient agar were confirmed biochemically by inoculating into Lysine Iron Agar (LIA), Triple Sugar Iron (TSI) Agar, Simmon Citrate (SC) agar Urea agar test, and motility test.

\section{Antimicrobial susceptibility testing}

All Salmonella isolates were tested for susceptibility to 13 different antimicrobial drugs using Kirby Bauer disc diffusion method as described by CLSI (2014). The antimicrobial impregnated discs (Oxoid Ltd, Hampshire, England) used were streptomycin, amikacin, gentamicin, amoxicillin, cefotaxime, ceftazidime, cefuroxime, chloramphenicol, ciprofloxacin, nitrofurantoin, tetra- 
cycline, trimethoprim-sulfamethoxazole and norfloxacin with appropriate concentration. Two to three pure colonies were picked up and emulsified in 3 to 4 $\mathrm{ml}$ of sterile normal saline. Dilution of the suspended colonies was performed until the turbidity matches the 0.5 McFarland Standards and transferred to Mueller-Hinton agar (HiMedia, Pvt. Ltd., India) using a sterile cotton swab. Following air drying the plates were incubated aerobically at $37^{\circ} \mathrm{C}$ for 18 to 24 hrs. The diameters of the zone of inhibitions were measured with a caliper and the susceptibility of the isolates was recorded as susceptible, intermediate, and resistant. Escherichia coli ATCC 35218 was used as quality control.

\section{Data analysis}

Data were entered into an MS Excel Spreadsheet and descriptive statistics were used to summarize the data. SATA version 11 (Stata Corp, 2009) for Windows was used for analysis. Prevalence was sorted by district, sex, age, and season, health status, diarrhea status, and organ. The association of the studied variables with the outcome variables was analyzed using logistic regression. Variables that were non-collinear and with P-value less than 0.25 during the univariable analysis were selected for multivariable logistic regression analysis. The odds ratio was used to compare the degree of association and the difference was considered significant when the P-value was less than 0.05 . The percentages of antimicrobial resistance (AMR) were calculated as susceptible, intermediate, and resistant.

\section{Ethical consideration}

Permission for this study was obtained from the Ambo University Animal Research Ethics Review Committee (ARERC) and conducted under the approved protocol Ref. No. RD/AREC/003/2015.

\section{Results}

\section{Clinical and postmortem findings}

The clinical signs recorded in sick chickens in this study were decreased appetite, depression, dehydration, weight loss, ruffled feathers, and watery to mucoid diarrhea, anemia with pale, and shrunken combs. Accordingly, out of the 205 chickens, $84(44.12 \%)$ and $121(55.88 \%)$ were clinically sick and apparently healthy, respectively. Salmonella culture positive spleen, liver, and kidney showed one or more of the pathological signs such as enlargement, 
congestion, white necrotic foci, and mottling. Ovarian follicles were regressed, misshapen, and discolored (Fig. 1). Out of 40 lesions, almost all were recorded from adult chickens.
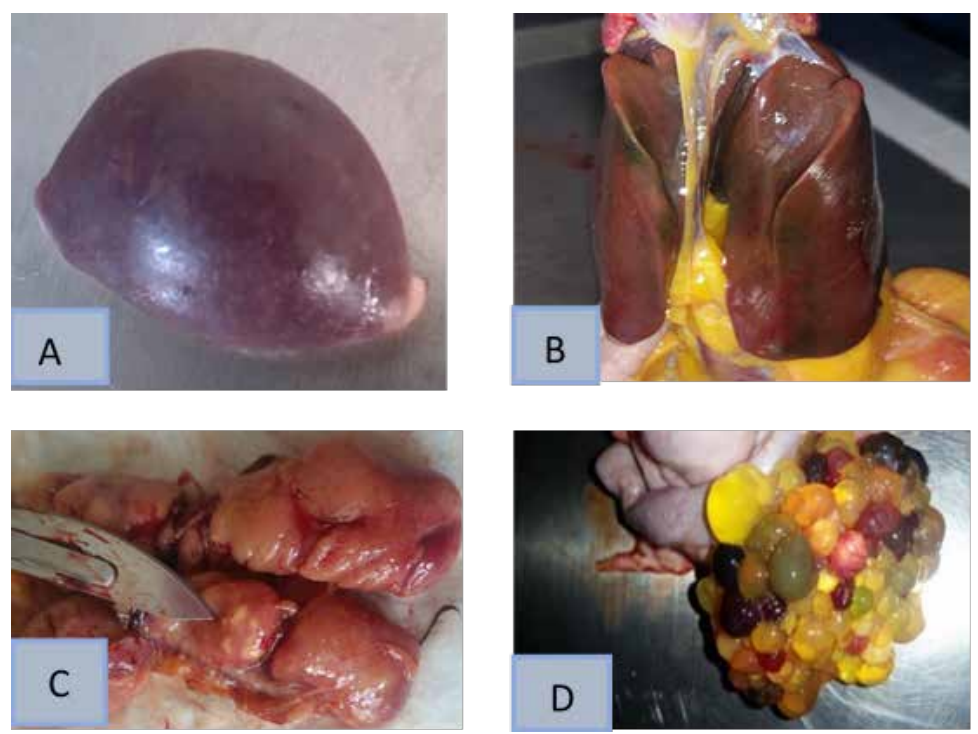

Figure 1. Gross lesions on Salmonella positive organs: enlarged and mottled spleen (A), discoloration and enlargement of the liver (B), enlargement and white spot appearance of kidney (C) discoloration and misshaping of ovarian follicles (D)

\section{Serological result}

Seroprevalence of $S$. Gallinarum was $63.5 \%$ (95\% CI: $55.9-70.5)$. According to the multivariable logistic regression analysis, the study site showed significant variation in seroprevalence $(\mathrm{p}<0.05)$, whereas other variables did not show significant association $(\mathrm{p}>0.05)$. Hence, chickens from the Guder area were with greater Odds of seropositivity ( $\mathrm{OR}=3.76,95 \% \mathrm{CI}: 1.09,12.98, \mathrm{p}=0.036)$ as compared to those from Dire Inchini (Table 1). 
Sarba et al.

Table 1. Logistic regression analysis of factors for seroprevalence of $S$. Gallinarum in poultry

\begin{tabular}{|c|c|c|c|c|c|c|}
\hline \multirow[t]{2}{*}{ Factors } & \multirow[t]{2}{*}{ Category } & \multirow{2}{*}{$\begin{array}{l}\text { No. } \\
\text { positive } \\
(\%)\end{array}$} & \multirow{2}{*}{$\begin{array}{l}\text { Univariable } \\
\text { OR (95\% CI) }\end{array}$} & \multicolumn{3}{|c|}{ Multivariable } \\
\hline & & & & $p$-value & $\begin{array}{l}\text { OR }(95 \% \\
\text { CI) }\end{array}$ & $p$-value \\
\hline \multirow[t]{2}{*}{ Breed } & Local & $95(62.9)$ & 1 & & & \\
\hline & Cross & $18(66.7)$ & $1.18(0.50,2.80)$ & 0.709 & & \\
\hline \multirow[t]{2}{*}{ Age } & Young & $60.6(60.6)$ & 1 & & & \\
\hline & Adult & $70(65.4)$ & $1.23(0.66,2.29)$ & 0.510 & & \\
\hline \multirow[t]{2}{*}{ Sex } & Male & $38(60.3)$ & 1 & & & \\
\hline & Female & $75(65.2)$ & $1.23(0.65,2.32)$ & 0.516 & & \\
\hline \multirow[t]{5}{*}{ Study site } & Dire Inchini & $17(41.5)$ & 1 & & - & - \\
\hline & Ijiaji & $11(44.0)$ & $1.11(0.41,3.03)$ & 0.840 & $\begin{array}{c}0.84 \\
(0.29,2.45)\end{array}$ & 0.754 \\
\hline & Ambo & $34(66.7)$ & $2.82(1.20,6.61)$ & 0.017 & $\begin{array}{c}1.82 \\
(0.59,5.60)\end{array}$ & 0.295 \\
\hline & Guder & $33(82.5)$ & $6.65(2.39,18.55)$ & 0.000 & $\begin{array}{c}3.76 \\
(1.09,12.98)\end{array}$ & 0.036 \\
\hline & Holeta & $18(85.7)$ & $8.47(2.15,33.37)$ & 0.002 & $\begin{array}{c}4.82 \\
(0.88,26.28)\end{array}$ & 0.069 \\
\hline \multirow[t]{2}{*}{ Season } & Wet & $38(46.3)$ & 1 & & - & - \\
\hline & Dry & $75(78.1)$ & $4.13(2.16,7.92)$ & 0.000 & $\begin{array}{c}2.15 \\
(0.91,5.14)\end{array}$ & 0.082 \\
\hline \multirow[t]{2}{*}{$\begin{array}{l}\text { Health } \\
\text { status }\end{array}$} & $\begin{array}{l}\text { App. } \\
\text { Healthy }\end{array}$ & $59(57.8)$ & 1 & & - & - \\
\hline & Sick & $54(71.0)$ & $1.79(0.95,3.367)$ & 0.070 & $\begin{array}{c}0.64 \\
(.20,2.02)\end{array}$ & 0.448 \\
\hline \multirow[t]{2}{*}{ Diarrhea } & Absent & $73(58.9)$ & 1 & & - & - \\
\hline & Present & $40(74.1)$ & $2.00(0.98,4.04)$ & 0.055 & $\begin{array}{c}2.00 \\
(0.62,6.48)\end{array}$ & 0.247 \\
\hline Total & & $113(63.5 \%)$ & & & & \\
\hline
\end{tabular}

\section{Culture-based prevalence}

From 205 chickens examined, 19.0\% (95\% CI: 13.9-20.1) were positive for Salmonella spp. About $38.5 \%$ (15/36) were non-motile, while $61.5 \%(24 / 39)$ of the isolates were motile. Of the 741 organs sampled, $7.3 \%$ (95\% CI: 5.5-9.4) were Salmonella positive. The isolation rates from the spleen, liver, ovaries, and kidneys were $11.2 \%, 7.0 \%, 6.1 \%$, and $4.4 \%$, respectively (Table 2 ). Not all the studied variables showed a significant difference $(p>0.05)$. However, a rel- 
atively higher isolation rate was observed in chickens of the Guder district (29.0\%) as compared to Ijaji (8.0\%), and adults (25\%) as compared to young chickens (23.1\%)(Table 3).

Table 2. The isolation rate of Salmonella from chicken organs

\begin{tabular}{lccc}
\hline Organ & No. of organs & No. positive & Isolation rate (\%) \\
\hline Spleen & 205 & 23 & 11.2 \\
Liver & 200 & 14 & 7.0 \\
Ovary & 131 & 8 & 6.1 \\
Kidney & 205 & 9 & 4.4 \\
Total & 741 & 54 & 7.3 \\
\hline Chi-square value $=3.47, p$-value $>0.05$ & &
\end{tabular}

Table 3. Prevalence of Salmonella compared with the breed, sex, age, study sites, season, health and status of diarrhea

\begin{tabular}{llccccc}
\hline Factors & Category & $\begin{array}{l}\text { No. of } \\
\text { chicken }\end{array}$ & $\begin{array}{l}\text { No. } \\
\text { positive } \\
\text { (\%) }\end{array}$ & $\begin{array}{l}\text { Odds } \\
\text { ratio }\end{array}$ & 95\% CI & $p$-value \\
\hline Breed & Cross & 30 & $4(13.3)$ & & & \\
& Local & 175 & $35(20.0)$ & 1.62 & $0.53,4.96$ & 0.390 \\
Sex & Female & 131 & $22(16.8)$ & & & \\
Age & Male & 74 & $17(22.9)$ & 1.47 & $0.73,3.00$ & 0.281 \\
& Young & 82 & $21(17.1)$ & & & \\
Site & Adult & 123 & $18(21.9)$ & 1.37 & $0.68,2.76$ & 0.384 \\
& Ijaji & 25 & $2(8.0)$ & & & \\
& Dire Inchini & 41 & $4(9.8)$ & 1.24 & $0.21,7.34$ & 0.810 \\
& Ambo & 68 & $14(20.6)$ & 2.98 & $0.63,14.18$ & 0.170 \\
Season & Holeta & 40 & $10(25.0)$ & 3.83 & $0.76,19.22$ & 0.102 \\
& Guder & 31 & $9(29.0)$ & 4.70 & $0.91,24.24$ & 0.120 \\
Health status & Wet & 98 & $15(15.3)$ & & & \\
& Dry & 107 & $24(22.4)$ & 1.60 & $0.78,3.26$ & 0.197 \\
Healthy & 121 & $21(17.4)$ & & & \\
\hline CI= Confidence interval & Sick & 84 & $18(21.4)$ & 1.30 & $0.64,2.62$ & 0.466 \\
& Diarrheic & 57 & $9(15.8)$ & & & \\
& Non-diarrheic & 148 & $30(20.3)$ & 1.35 & $0.60,3.07$ & 0.465 \\
& & 205 & $39(19.0)$ & & & \\
\hline
\end{tabular}

Ethiop. Vet. J., 2020, 24 (2), 73-89 


\section{Antimicrobial susceptibility}

Salmonella isolates showed higher susceptibility to norfloxacin (97.4\%), chloramphenicol (92.3\%), trimethoprim-sulfamethoxazole (89.7\%) and streptomycin (84.6\%). All the isolates were resistant to amoxicillin, tetracycline, and nitrofurantoin, thus $100 \%$ multidrug-resistant (MDR) to these three antimicrobial classes (Table 4). Besides, three different MDR patterns to six antimicrobial classes were observed. Four isolates were multidrug-resistant to five antimicrobial classes (Table 5).

Table 4. Antimicrobial susceptibility test of Salmonella isolates

\begin{tabular}{|c|c|c|c|c|c|c|}
\hline $\begin{array}{l}\text { Antimicrobial } \\
\text { class }\end{array}$ & $\begin{array}{l}\text { Antimicrobial } \\
\text { Agent }\end{array}$ & $\begin{array}{l}\text { Disc } \\
\text { Code }\end{array}$ & $\begin{array}{l}\text { Potency } \\
\text { ( } \mu g)\end{array}$ & $\begin{array}{l}\text { No. }(\%) \\
\text { resistant }\end{array}$ & $\begin{array}{l}\text { No. }(\%) \\
\text { interm } \\
\text { ediate }\end{array}$ & $\begin{array}{l}\text { No. }(\%) \\
\text { suscep } \\
\text { tible }\end{array}$ \\
\hline \multirow[t]{3}{*}{ Aminoglycosides } & Streptomycin & $\mathrm{S}$ & 10 & $2(5.1)$ & $4(10.3)$ & $33(84.6)$ \\
\hline & Amikacin & AMK & 30 & 0 & $10(25.6)$ & $29(74.4)$ \\
\hline & Gentamycin & GEN & 10 & 0 & $15(38.5)$ & $24(61.5)$ \\
\hline B-lactams & Amoxicillin & AMX & 25 & $39(100)$ & 0 & 0 \\
\hline \multirow[t]{3}{*}{ Cephems } & Cefotaxime & CTX & 30 & 0 & $10(25.6)$ & $29(74.3)$ \\
\hline & Ceftazidime & CAZ & 30 & $5(12.8)$ & $5(12.8)$ & $29(74.4)$ \\
\hline & Cefuroxime & CRX & 30 & $3(7.7)$ & $21(53.8)$ & $15(38.5)$ \\
\hline Phenicols & Chloramphenicol & $\mathrm{CHL}$ & 30 & $3(7.7)$ & 0 & $36(92.3)$ \\
\hline Quinolones & Ciprofloxacin & CPR & 5 & 0 & $20(51.3)$ & $19(48,7)$ \\
\hline Nitrofurans & Nitrofurantoin & NIT & 300 & $39(100)$ & 0 & 0 \\
\hline Tetracyclines & Tetracycline & TET & 30 & $39(100)$ & 0 & 0 \\
\hline $\begin{array}{l}\text { Folate pathway } \\
\text { inhibitors }\end{array}$ & $\begin{array}{l}\text { Trimethoprim- } \\
\text { sulfamethoxazole }\end{array}$ & $\mathrm{SXT}$ & 23.75 & 0 & $4(10.3)$ & $35(89.7)$ \\
\hline Fluoroquinolones & Norfloxacin & NOR & $10 \mu \mathrm{g}$ & 0 & $1(2.6)$ & $38(97.4)$ \\
\hline
\end{tabular}

Table 5. Resistance patterns in Salmonella isolated from chicken ( $=39)$

\begin{tabular}{llc}
\hline Number & Antimicrobial resistance pattern & No. of resistant isolates (\%) \\
\hline Three & AMX TET NIT & $39(100)$ \\
Four & AMX TET NIT CRX & $20(51.3)$ \\
Five & AMX TET NIT SXT CHL & $4(10.3)$ \\
AMX Amoxicillin, TET Tetracycline, NIT Nitrofurantoin, CRX Cefuroxime, SXT Trimethoprim-sulfamethoxa- \\
zole, CHL Chloramphenicol.
\end{tabular}




\section{Discussion}

Salmonella in poultry causes heavy losses through mortality and reduced production (Jordan and Pattison, 1996). The current study revealed $63.5 \%$ seropositivity to chicken salmonellosis, which is in agreement with $61.7 \%$ report of Sundar et al. (2007) and 64.2\% Ashenafi et al. (2003). However, the present finding was higher than the $35.9 \%$ reported by Afera et al. (2012) from Ethiopia and 45.9\% seroprevalence reported by Ahmed et al. (2008) from Bangladesh. The possible causes of the high prevalence recorded in this study could be the reason that salmonellosis in chicken is complicated by vertical and horizontal transmission. Subclinical carrier layer chickens might pass the infections to their embryos in the egg and to the rest of the flock, as there is no practice of culling carrier chickens in most of the chicken keeping communities in Ethiopia. The higher odds of seropositivity in Guder as compared to chickens from Dire Inchini could be due to possible contamination of chicken in the nearby village chickens from sick chicken brought to the big livestock market at Guder.

The $19.0 \%$ culture-based prevalence of Salmonella in the current study was comparable to a $16.7 \%$ reported by Abdi et al. (2017) but much higher than the 8\% reported by Aragaw et al. (2010) using direct cloacal swab plating technique. This high prevalence in the present study could be related to the higher probability of Salmonella detection from spleen, liver, ovary, and kidney of carrier chickens. In this study, 38.5\% of the isolates were non-motile and are either $S$. Gallinarum or $S$. Pullorum which are responsible for active clinical cases or chronic carrier state.

The organ level isolation rate was $7.3 \%$, which is lower than $19.7 \%$ in China (Li et al., 2013). Higher prevalence such as 47\% (Uyttendaele et al., 1999), and $23 \%$ were also reported(Alali et al., 2012). In these studies, Salmonella contamination from the surface of the retail chicken carcass was the target, which could result in a higher prevalence rate compared to chicken organs that are free of any external contamination. The higher detection rate of Salmonella spp. in the spleen (11.2\%) and liver (7.0\%) compared to ovaries (4.4\%) in the current study is nearly in line with the report of Rahimi (2012) from Iran who reported 14\% (spleen), 6\% (liver), and 4\% (ovaries). Nazir et al. (2014) reported that the liver and spleen were the primary target organs involved in $S$. Gallinarum infection, irrespective of the route of infection. The infected liver and spleen were characterized by lesions such as hepatomegaly, discoloration of 
liver, splenomegaly, congestion, and necrotic foci (Nazir et al., 2012). This is in line with the current finding of lesions in the positive liver and spleen.

The lower detection rate of Salmonella spp. in young (17.1\%) than adult (21.9\%) chickens in the present study are in agreement with the reports of Temelli et al. (2012). According to Zewdu and Cornelius (2009), the prevalence of Salmonella increased with the increasing age of chickens. Generally, Salmonella in adult chickens might be attributed to the physiological stress of layers during egg-laying and molting, which depress their immune response and increase the susceptibility as compared to young chickens (Landers et al., 2005). In this study, there was a lower detection rate of salmonella from exotic than local chickens. This could be because most of the exotic chickens sampled in the present study were growers recently distributed to farmers from the growing center, which are not expected to be the carrier. Moreover, the sample size of exotic chickens is small. The absence of a significant association of Salmonella detection rate and seropositivity with sick chicken could be because the clinical signs considered were not specific and some of the isolates might not be pathogenic to chicken.

Antimicrobial resistance in Salmonella spp. has been a global problem, with the rates increased to as high as $70 \%$ in some countries (Su et al., 2004). In the present study, 100\% resistance to amoxicillin, tetracycline, and nitrofurantoin are in accordance with the $100 \%$ resistance to amoxicillin and tetracycline (Hassan et al., 2014), 100\% to nitrofurantoin (Rampling et al., 1990), and $97.8 \%$ to tetracycline (Abdi et al., 2017). In contrast to the present finding, a lower resistance rate of Salmonella from poultry farms was reported to the aforementioned antimicrobials (Eguale, 2018; Dagnew et al., 2020). This variation could be due to the different samples considered which in turn might also be associated with different serovars. The other probable reason could be that most chickens in this study were obtained from local chicken traders who use different antimicrobials unprofessionally for prophylaxis in healthy and treatmentof sick chickens, that might result in possible contamination with resistant strains. The MDR at least to three antimicrobials used which is similar to the pevious report (Yildirim et al., 2011). The absence of resistance to norfloxacin indicates that the drug is a reserve drug as reported by Lee et al. (2005). These reports indicate that the utilization of antimicrobials is different from region to region and between antimicrobials themselves. 
The finding of MDR to six antimicrobial classes in the present study supports the report of Abdi et al. (2017) who reported resistance isolates from chicken to 8 antimicrobials. The current finding supports the idea that Salmonellae are among the most known bacteria to carry plasmids, which encode for drug resistance (Poppe et al., 2002). The widespread use of antimicrobials in animals/humans might cause an increase in the frequency of bacteria resistant to other antimicrobials as the $\mathrm{R}$ plasmid may encode resistance to additional antimicrobials.

Generally, poor hygiene and biosecurity, undeveloped diagnostic capabilities, lack a strong system for notification of pathogens, and antimicrobial resistance could contribute to higher disease burden in Ethiopia (Pagani and Wossene, 2008). However, the limitation of genotype data and the inability to get enough information from chicken owners in the present study made it difficult to analyze their role on pathogenesis and risk factor for drug resistance, respectively. According to ISO 2002, parallel selective enrichment- RP and Tetrathionate are recommended, but as the latter doesn't support the growth of $S$. Gallinarum and $S$. Pullorum we didn't use it, which might have affected the isolation rate of another Salmonella serotypes.

\section{Conclusion}

The present study revealed Salmonella is prevalent in chickens in the study areas. A higher isolation rate of Salmonella was recorded in the spleen and liver. A considerable number of Salmonella isolates from chickens were multidrug-resistant to antimicrobial drugs commonly used for animals and humans. Therefore, there is a need for regular surveillance and monitoring of salmonellosis and antimicrobial resistance. Awareness creation for chicken farmers about improving farming practices and the risks of antimicrobial resistance warrants special attention.

\section{Acknowledgments}

Ethiopian Institute of Public Health is acknowledged for giving us antimicrobial discs and reference organisms and Ambo University for funding this research. 


\section{References}

Abdi, R.D., Mengstie, F., Beyi, A.F., Beyene, T., Waktole, H., Mammo, B., et al., 2017. Determination of the sources and antimicrobial resistance patterns of Salmonella isolated from the poultry industry in Southern Ethiopia. BMC Infect.Dis.,17, 352352.

Afera, B., Regassa, F., Issa, A., 2012. Seroprevalence of fowl typhoid in selected sites of East Shewa, Ethiopia. Rev. Electron. Vet.,13(9).

Ahmed, A., Islam, M., Haider, M., andHossain, M., 2008. Seroprevalence and pathology of naturally infected salmonellosis in poultry with isolation and identification of causal agents. J. Bangladesh Agri. Univ.,6, 327-334.

Alali, W.Q., Gaydashov, R., Petrova, E., Panin, A., Tugarinov, O., Kulikovskii, A., et al., 2012. Prevalence of Salmonella on retail chicken meat in the Russian Federation.J. Food Prot., 75, 1469-1473.

Aragaw, K., Terefe, L., and Abera, M., 2010. Prevalence of Salmonella infection in intensive poultry farms in Hawassa and isolation of Salmonella species from sick and dead chickens. Ethiop. Vet. J. 14, 115-124.

Ashenafi, H., Shetu, Y., andOldemeskel, M., 2003. Identification of major infections of local chickens of Central Ethiopia. Bull. Anim. Hlth. Prod. Afr.,51, 95-101.

Bekele, B., and Ashenafi, M., 2010. Distribution of drug resistance among enterococci and Salmonella from poultry and cattle in Ethiopia. Trop. Anim.Hlth. Prod.,42, 857-864.

Berhe, N., Afera, B., Abebe, N., Tesfaya, A., and Kalayou, S., 2012. Seroprevalence of Salmonella pullorum infection in local and exotic commercial chicken from Mekelle areas, northern Ethiopia. Rev. Electron. Vet., 13, 9.

Calnek, B.W., Barnes, H.J., Beard, C.W., Mcdougald, L.R., and Saif, Y.M.,1991. Diseases of Poultry. 10 ${ }^{\text {th }}$ edn. Iowa State University Press, Ames, USA. 81-130.

Chaka, H., Goutard, F., Bisschop, S.P., and Thompson, P.N., 2012. Seroprevalence of Newcastle disease and other infectious diseases in backyard chickens at markets in Eastern Shewa zone, Ethiopia. Poult. Sci.,91, 862-869.

Chanie, M., Negash, T., and Tilahun, S.B., 2009. Occurrence of concurrent infectious diseases in broiler chickens is a threat to commercial poultry farms in Central Ethiopia. Trop. Anim. Hlth Prod., 41, 1309.

Chauhan, H.V.S., and Roy, S., 2007. Poultry Diseases Diagnosis and Treatment, $3^{\text {rd }}$ ed, New International Limited, New Delhi, pp 18-27.

CLSI, 2014. M100-S24 Performance Standards for Antimicrobial Susceptibility Testing: Twenty Fourth Information Supplement, pp 68-150. 
DACA, 2009. Antimicrobials use resistance and containment baseline survey syntheses of findings. Addis Ababa.

Eguale T. Prevalence and antimicrobial susceptibility of Salmonella in poultry farms and in-contact humans in Adama and Modjo towns, Ethiopia. MicrobiologyOpen. 2020;9:e1067.

Dagnew, B., Alemayehu, H., Medhin, G., and Eguale, T., 2020. Prevalence and antimicrobial susceptibility of Salmonella in poultry farms and in-contact humans in Adama and Modjo towns, Ethiopia. Microbiol. Open, 9:e1067.

Eguale, T., 2018. Non-typhoidal Salmonella serovars in poultry farms in central Ethiopia: prevalence and antimicrobial resistance. BMC Vet. Res., 14:217.

Etefa, Y., and Dibaba, K., 2011. Physical and socio-economic profile of west Shewa zone and districts'. Bureau of finance and economic development regional data and information core process organized by regional socio-economic profile experts. Addis Ababa: The NRG of Oromia.

Gal-Mor, O., 2019. Persistent Infection and Long-Term Carriage of Typhoidal and Nontyphoidal Salmonellae. Clin. Microbiol. Rev., 32(1), e00088-18.

Hassan, M.M., Amin, K.B., Ahaduzzaman, M., Alam, M., Faruk, M.S., andUddin, I., 2014. Antimicrobial resistance pattern against E. coli and Salmonella in layer poultry. Res. J. Vet. Pract., 2, 30-35.

ISO, 2002. ISO 6579(2002) Amend1: 2007. Microbiology of food and animal feeding stuffs - Horizontal method for detection of Salmonella spp.

Jordan, F., andPattison, M., 1996. Reoviridae. Poultry Diseases, 4th ed. WB Saunders Company Ltd, London, 218-222.

Kindu, A., and Addis M., 2013. A survey on Salmonella infection among chicken flocksin Jimma town, Ethiopia. Afr. J. Microbiol. Res., 7(14), 1239-1245.

Landers, K., Woodward, C., Li, X., Kubena, L., Nisbet, D., and Ricke, S., 2005. Alfalfa as a single dietary source for molt induction in laying hens. Bioresource. Technol., $96,565-570$.

Lee, Y.-J., Kim, A.-R., Jung, S.-C., Song, S.-W., andKim, J.-H., 2005. Antibiotic resistance pattern of $E$. coli and Salmonella spp. isolated from chicken feces. Korean. J. Vet. Res., 45, 75-83.

Li, R., Lai, J., Wang, Y., Liu, S., Li, Y., Liu, K., et al., 2013. Prevalence and characterization of Salmonella species isolated from pigs, ducks, and chickens in Sichuan Province, China. Int. J. Food Microbiol.,163, 14-18. 
Molla, B., Mesfin, A., and Alemayehu, D., 2003. Multiple antimicrobial-resistant Salmonella serotypes isolated from chicken carcass and giblets in Debre Zeit and Addis Ababa, Ethiopia. Ethiop. J. Hlth. Dev., 17 (2), 131-149.

Muktaruzzaman, M., Haider, M., Ahmed, A., Alam, K., Rahman, M.M., Khatun, M.B.,Rahman, M.H. and Hossain, M.M.2010. Validation and refinement of Salmonella pullorum (SP) colored antigen for diagnosis of Salmonella infections in the field. Int. J. Poult. Sci., 9, 801-808.

Nazir, Sh., Ahmad K.Sh., Maqbool D.M., Saleem M.M., Ahmad K. F., and Amare A., 2012. Pathology of spontaneously occurring salmonellosis in commercial broiler chickens of Kashmir Valley. J. World's Poult. Res., 2(4), 63-69.

Nazir, S., Kamil, S.A., Riyaz, A., Mir, M.S., Darzi M.M., Yasine A., and Goudar, K.S., 2014. Pathology and colonization of internal organs after experimental infection of broiler chickens with Salmonella Gallinarum through oral or intraperitoneal routes. Rev.Elev. Med. Vet. Pays Trop., 67 (2), 53-60.

OIE, 2012. Fowl typhoid and pullorum disease: In Manual of diagnostic tests and vaccines for terrestrial animals. Chapter 2.3.1, pp 978-92, Paris, France.

Pagani, P., andWossene, A., 2008. Review of the new features of the Ethiopian poultry sector. Biosecurity implications. Food and Agriculture Organization of the United Nations (FAO).

Parveen, S., Taabodi, M., Schwarz, J.G., Oscar, T.P., Harter-Dennis, J., andWhite, D.G., 2007. Prevalence and antimicrobial resistance of Salmonella recovered from processed poultry. J. Food Prot., 70, 2466-2472.

Poppe, C., Ziebell, K., Martin, L., andAllen, K., 2002. Diversity in antimicrobial resistance and other characteristics among Salmonella Typhimurium DT104 isolates. Microb. Drug Resist.,8, 107-122.

Quinn, P., Markey, B., Leonard, F., FitzPatrick, E., Fanning, S., andHartigan, P., 2011. Veterinary Microbiology and Microbial Disease Second Edition. Homestar, Syndey.

Rahimi, E., 2012. Prevalence and antimicrobial resistance of Salmonella spp isolated from retail chicken, turkey, and ostrich by-products in Iran. Rev. Méd.Vét.,163, 271-275.

Rampling, A., Upson, R., andBrown, D.F., 1990. Nitrofurantoin resistance in isolates of Salmonellaenteritidis phage type 4 from poultry and humans. J. Antimicrob. Chemother.,25, 285-290.

Sambo, E., Bettridge, J., Dessie, T., Amare, A., Habte, T., Wigley, P. 2015. Participatory evaluation of chicken health and production constraints in Ethiopia. Prev. Vet. Med., 118, 1117-127. 
Sanchez, S., Hofacre, C.L., Lee, MD., Maurer, J.J., andDoyle, M.P., 2002. Animal sources of salmonellosis in humans. J. Am. Vet. Med. Assoc., 221(4), 492-497.

Stata Corp, T., 2009. Statistical Software: Release 11 College Station, College Station, TX: StataCorp LP., USA.

Su, L.-H., Chiu, C.-H., Chu, C., andOu, J.T., 2004. Antimicrobial resistance in nontyphoid Salmonella serotypes: a global challenge. Clin. Infect. Dis.,39, 546-551.

Sundar, J., Rai, R., Kundu, A., Senani, S., Chatterjee, R., andJeyakumar, S., 2007. Seroprevalence of poultry diseases in the Andaman and Nicobar Islands. Indian Vet. J., 84, 95-96.

Temelli, S., Eyigor, A., andCarli, K., 2012. Salmonella detection in poultry meat and meat products by the Vitek immunodiagnostic assay system easy Salmonella method, a LightCycler polymerase chain reaction system, and the International Organization for Standardization method 6579. Poult. Sci.,91, 724-731.

Thrusfield, M., 2007. Describing disease occurrence. Veterinary epidemiology. $3^{\text {rd }}$ edition. Blackwell Publishing, pp 46-74.

Tufa, T.B., Gurmu, F., Beyi, A.F. Hogeveen, H., Beyene, T. J., Ayana, D., et al., 2018. Veterinary medicinal product usage among food animal producers and its health implications in Central Ethiopia. BMC Vet. Res., 14, 409.

Uyttendaele, M., De Troy, P., andDebevere, J., 1999. Incidence of Salmonella, Campylobacterjejuni, Campylobacter coli, and Listeria monocytogenes in poultry carcasses and different types of poultry products for sale on the Belgian retail market. $J$. Food Prot., 62, 735-740.

Yildirim, Y., Gonulalan, Z., Pamuk, S., andErtas, N., 2011. Incidence and antibiotic resistance of Salmonella spp. on raw chicken carcasses. Food Res. Int., 44, 725-728.

Zewdu, E., and Cornelius, P., 2009. Antimicrobial resistance pattern of Salmonella serotypes isolated from food items and personnel in Addis Ababa, Ethiopia. Trop. Anim. Hlth. Prod., 41, 241. 